Article

\title{
Future Professionals: A Study of Sustainable Behavior
}

\author{
Vanderleia Martins Lohn ${ }^{1}{ }^{*}$, Rafael Tezza ${ }^{2}$, Graziela Dias Alperstedt ${ }^{2}$ and Lucila M. S. Campos ${ }^{3}$ \\ 1 Post-Graduate Program in Production Engineering, Federal University of Santa Catarina (UFSC), \\ 88040 Florianopolis, Brazil \\ 2 College of Administration and Economic Science, State University of Santa Catarina (UDESC), \\ 88040 Florianopolis, Brazil; rafaeltezza@yahoo.com.br (R.T.); gradial@gmail.com (G.D.A.) \\ 3 Department of Production Engineering and Systems, Federal University of Santa Catarina (UFSC), \\ 88040 Florianopolis, Brazil; lucila.campos@ufsc.br \\ * Correspondence: vandalohn@hotmail.com; Tel.: +55-48-3721-7001; Fax: +55-48-3721-7000
}

Academic Editor: Marc A. Rosen

Received: 3 July 2016; Accepted: 8 November 2016; Published: 10 March 2017

\begin{abstract}
Sustainability in an organizational environment involves a form of management that allows attaining a balance between the economic, environmental and social dimensions, and can contribute to the sustainable behavior of employees and administrators. Nevertheless, studies that evaluate sustainable behavior of future professionals using a multidimensional approach to create a scale to measure sustainable behavior of students are relatively rare and there is a need for research in this field. Therefore, the objective of this article is to analyze the sustainable behavior of potential professionals, using the multidimensional approach of item response theory (IRT). A set of 13 items evaluated by specialists and tested by graduate students was applied to 492 undergraduate students from a community university in Southern Brazil in the schools of administration, human resources, accounting, law, civil engineering and biology. The results indicate that the students have higher sustainable behavior in the social dimension and lower in the economic dimension, highlighted by participation in voluntary activities. This result can provide important information to companies, given that in their processes for recruiting and selecting new employees, many have included issues related to sustainable practices, not only from an economic perspective, but particularly from environmental and social perspectives.
\end{abstract}

Keywords: sustainable behavior; sustainability; undergraduate students; item response theory (IRT)

\section{Introduction}

The issue of sustainability has been widely studied due to the environmental effects of human influence on nature, as well as the need to adapt to the market due to pressure from consumers and interested parties [1-3]. Companies have been increasingly challenged to see that their results and sense of responsibility transcend economic objectives [4-7], which heightens the importance of the organizational and institutional levels of analysis.

In this context, changes are increasingly necessary to guarantee the availability of natural resources to future generations, particularly in the role of companies in product development and in the harmonization of the economic, environmental and social spheres in the strategic positions of corporations [4-6,8]. Related to these factors, studies conducted in developed countries, such as Germany, Canada, Hungary and the United States have found that companies that are motivated to adopt sustainability practices have better economic and environmental performance, market position, competitive advantage and a commitment to employees and the local community [9]. 
Although there is extensive literature about the issue, authors such as Aguinis and Glavas highlight the need for studies related to the individual level of analysis, and clarify that this level of analysis has direct reflections on the organizational level when, for example, individuals with sustainable or even pro-environmental behavior occupy strategic positions. That is, there is a recursive relationship between the levels of analysis. Moreover, the challenges of the transition to more sustainable models are enormous because they involve holistic and multidisciplinary approaches [10]. These are presumptions of this study. It is understood that companies reflect not only institutional forces, but individuals whose behavior tends to be transferred to organizational and societal systems, thus influencing other individuals or groups. That is, the changes necessary are based on changes in individual behavior [11].

These "sustainable leaders" are, as mentioned by Ferdig, decision makers and administrators dedicated to a more sustainable society [12]. A sustainable leader is engaged in the creation of transformative changes among other individuals and groups, aiming for an economically, environmentally and socially sustainable future. In this sense, there is a certain agreement about the idea that an organizational culture dedicated to sustainability will only be incorporated by markets when companies have more leaders who are passionate about the idea of transformation. Therefore, individual values are subjacent to the supposition of this work as well as the congruence of these individual values with organizational values [13-15], considering the relationship between personal values and their impact on decision making, given that values influence the perception of administrators, which leads to the understanding that individuals with pro-environmental behavior have values that sustain them $[16,17]$.

Considering this discussion, an important factor of individual influence is related to the education of individuals [18], which calls attention to the role of educational institutions in making individuals aware of the importance of supporting more sustainable values. That is, the main actor in the changes needed for a company to become sustainable is the individual, and for this reason, the people involved should be aware of their role in corporate decision-making.

In this context, Laessoe and Mochizuki have described the concern of the United Nations and United Nations Educational, Scientific and Cultural Organization (UNESCO) about climate change and the emphasis these institutions give to the importance of education about sustainable development. They emphasize the role of national governments in the promotion of educational systems and the need to develop new initiatives and competencies related to the green economy [19].

Multiple researchers have also highlighted the role of human capital as a requirement for attaining sustainability [1,20], emphasizing the challenge of organizations to put this into practice, given that the education of citizens and professionals in this field is still at an early stage. That is, it is necessary to invest in the awareness and education of professionals regarding more sustainable behavior, not only within companies, but also in situations of social conviviality.

Thus, based on the findings presented, this article is justified by the need for studies that evaluate the behavior of future professionals (undergraduate students) who will be entering the labor market, to better understand sustainability practices, given that for corporate environments this information can contribute to attaining objectives related to the social, environmental and even economic performance of a company. That is, it is necessary to identify: the attitudes that have been developed and those that need to change to guarantee the sustainability of future generations; what sustainable behaviors are practiced by future professionals; and what companies must do internally or even in the selection and recruitment process in relation to the practice of sustainability; among other important questions such as what universities must do to prepare future professionals who have more sustainable behavior.

Based on the justifications presented and considering that higher education institutions have a strategic role in establishing a change in the sustainable behavior of future professionals, the objective of this article is to analyze the sustainable behavior of potential professionals, using the multidimensional approach of item response theory (IRT). 
In the humanities and the social sciences, the evaluation of human behavior in a certain field is usually analyzed with certain constructs, which are not, however, directly observed on a scale of comparative values of their items (issues in a questionnaire) that are properly organized in the interest of a latent trait. In this sense, IRT is a statistical technique that involves a group of mathematical models whose objective is to represent the probability that a respondent will describe a certain response to an item as a function of the parameters of the item and the ability of the respondent, highlighting that the greater the ability of the respondent, the greater the probability of answering the question correctly [21]. Thus, IRT stands out among other statistical techniques because it can construct a scale on which items and respondents can be positioned and compared. In this study, to address a multidimensional characteristic - the sustainable behavior of students-multidimensional models of IRT were used.

\section{Sustainability and Human Resources}

Sustainability has become increasingly important for research in the area of administration in recent decades due to the rapid depletion of natural resources and concerns about the distribution of wealth and the social responsibility of organizations. Within this perspective, business performance has been evaluated not only in economic terms, but also in terms of its impacts on the environment and stakeholders [1,22]. Given the importance of changes in values and practices related to sustainability, the field of human resources has gained strategic importance among services related to social and environmental performance objectives.

In a paper by Jabbour and Santos, we are reminded that human resource management is the organizational area that presents the greatest potential for incorporating themes such as sustainability and that specific strategies should be developed for this purpose [23]. Additionally, it is important to emphasize that people play a central role in organizations, and that the field of human resources can stimulate the inclusion of sustainability issues among the various relationships a company has with its internal and external stakeholders [24].

The idea that people are not only internal stakeholders but also sources of competitive advantage is not new in business management $[10,25]$. This aspect, however, is especially important when considering sustainability-oriented human skills, in which values and behaviors become difficult to imitate [26]. This may represent a potential source of competitive advantage, since "mental sustainability" is crucial to the implementation of sustainable strategies not only from an economic standpoint, but especially from environmental and social perspectives.

In a paper by Wright and Boswell, whose analysis has highlighted the importance of research on people management have added two dimensions to the discussion: the macro approach and the micro approach. The macro approach relates to the concerns of the organization as a whole, such as human resources planning, codes of conduct and human resources policies. The micro level focuses on individuals and considers practices such as recruitment, selection, compensation and individual performance assessment [27].

Considering people as the most prominent resource, the literature on human resources and sustainability is still emerging and, according to Dao et al., in an embryonic stage. The field is dedicated to the alignment of human capital, the management of talents, training and development as important functions of human resources in the scope of sustainability issues [28].

Jabbour and Santos [23] also highlight the critical role that human resources has in the development of organizational sustainability, through practices that promote environmental performance, innovation and the efficient management of diversity. The goal is to create systems focused on the range of economic objectives, but also on people and the objectives for the planet [1].

Some studies seek to highlight the importance of the area of human resources in corporate sustainability. This is the case of Wirtenberg et al., who identified seven essential qualities of sustainable companies and mapped specific actions related to the field of human resources to help develop these qualities [28]. Another study by Fenwick and Bierma demonstrated the need for greater engagement of the area of human resources to achieve greater social and environmental responsibility [29]. 
However, the literature review conducted by Dao et al. showed the lack of a holistic approach that integrates the area of human resources with other organizational resources to develop sustainable capacities [1]. Jabbour and Santos [23] proposed a model in which human resources management is aligned to organizational objectives related to innovation management, the management of cultural diversity and the continual improvement of environmental management. Moreover, all human resource practices are conducted to support organizational sustainability, given that the objectives of innovation management, cultural diversity and environmental management ought not to contradict each other [1].

This study focuses on undergraduate students, who serve as an example of future professionals of companies who have the potential to develop values and sustainable business practices. Considering that recruitment and selection aim to provide companies with people who are aligned with the corporation's strategic objectives and values, it is assumed that the more compatible the individual profiles are with broader organizational goals, the greater are the chances of success.

\section{Item Response Theory (IRT)}

In the area of applied social sciences it is common for researchers and professionals to be interested in measuring latent traits-i.e., not directly measurable characteristics. The creation of measurement tools in this context generally counts on the development of questionnaires, surveys and qualitative or quantitative variables through surveys. The most common treatments for variables of this type are structural equation modeling, logistic regression and factorial analysis among others. Nevertheless, these techniques identify factors and relationships but do not create standardized scales that allow positioning items or variables and the responding individuals in a comparable manner. In this sense, Multidimensional Item Response Theory (MIRT) presents itself as a multivariate technique that allows not only evaluating multidimensional structures and verifying their relations, but also creating a scale.

IRT is composed of a set of probabilistic models that relate a latent trait of a respondent $(\theta)$, something that cannot directly be measured, with the probability that the respondent will respond to an item with a determined category [18]. The application of IRT requires developing some initial presuppositions such as the determination of the model of the IRT that best fits the data set to be analyzed and the objectives of the investigation. Another important assumption, which also depends on the determination of the model, is the determination of the dimensionality of the latent trait, i.e., the measured value of the latent traits. According to Singh, dimensionality refers to the number of factors needed to explain the variability of the data and form a hypothesis to be verified [30].

IRT, in its uni-dimensional models, is currently being used by companies to measure work attitudes [31,32], personality [33,34], general mental ability [35], performance appraisals [36], professional interests [37] and the opinions of employees [38]. According to a paper by Allen and Wilson, despite developments in the methodological literature, the application of MIRT models in different educational fields has been limited [39]. This is probably because of (1) the problems of complexity in the statistical calculations involved in these models; and (2) the difficulty associated with the interpretation of multidimensional models.

In this context, the application of IRT depends particularly on the choice of the most appropriate model, considering the nature and dimensionality of the data. The definition of the dimensionality depends on the structure of the items as well as the respondents. In general, it can be hierarchical or non-hierarchical, with correlated factors or not. As to the nature of the data, it is most common to work with cumulative items, which can be dichotomous, ordinal or nominal polytomous, among others.

Regarding the IRT models, the so-called hierarchical MIRT models, Gibbons and Hedeker generalized the classical work of Holzinger and Swineford [38] and proposed the full-information bi-factorial (FI bi-factorial) model for dichotomous data [40,41]. This model consists of a general factor and group factors or independent dimensions. The FI bi-factorial model assumes the presence of a general factor that encompasses all the items and two or more groups of factors (or dimensions) corresponding to the specific subgroups [21]. 
For binary data, the bi-factorial model can be defined as a particularization of the multidimensional compensatory model [42]. In the case of the bi-factorial model, the restriction of loading discrimination parameters is inserted as shown in Equation (1):

$$
P\left(U_{i j}=1 \mid \theta_{j g}, \theta_{j e s k}\right)=\frac{e^{\left[\left(a_{i g} \theta_{j g}+a_{i e s k} \theta_{j e s k}\right)-d_{i}\right]}}{1+e^{\left[\left(a_{i g} \theta_{j g}+a_{i e s k} \theta_{j e s k}\right)-d_{i}\right]}}
$$

in which the ability of the respondent $j$ is in the general factor. Where the ability of the respondent $j$ is in the specific factor $k, a_{i g}$ represents the parameter of discrimination of item $i$ in the general factor, and $a_{i e s k}$ represents the parameter of discrimination of item $i$ in specific factor $k$. Finally, $d_{i}$ represents the scaling of the parameter of difficulty of item $i$ referring to the general dimension and the specific dimension $k$. In this model, as well as the compensatory multidimensional model, the responses are assumed to be statistically independent.

According to Gibbons et al. [40], the FI bi-factorial model is always relevant when the items share a common characteristic. The presence of subgroups of items typically introduces the relevant associations to a test that cannot be verified with a total allocation of the loads to the general factor [40]. Moreover, according to the Gibbons et al. [40], this separation of factors improves the errors in estimation. Figure 1 contextualizes the FI bi-factorial model within the multidimensional structure.

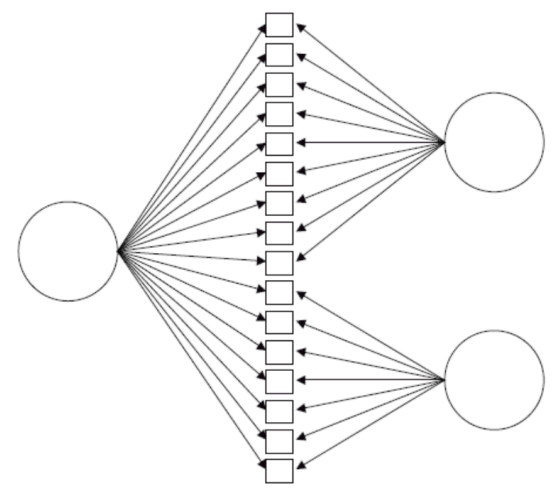

Figure 1. Four possible structures of latent traits [36]. Within the bi-factorial model there is a general factor that explains the correlations between items, but there are also the so-called "group" factors (on the right side of the figure) that attempt to capture the covariance of the items that are independent of the general covariance factor.

\section{Research Method}

To reach the goal proposed in this paper, an exploratory study was carried out of the sustainable behavior of undergraduate students using IRT. The IRT methodology was chosen because it is the only statistical tool that creates a scale and positions items and respondents within it.

The study uses a quantitative approach, with a non-random sample. To implement the approach the study defined: the nature of the polytomous item; the population; and the amount of the latent trait that is being measured as one. It is worth noting that IRT allows identifying items with differential functioning in different groups, equalizing scores of different forms of the same test and interpreting test scores on a single scale $[43,44]$. In this study, the latent trait is the sustainable behavior of the undergraduate students. The questions were prepared based on the triple bottom line of sustainability (environmental, social and economic aspects) and on research questions prepared by the Akatu Institute [45], a non-governmental non-profit organization that works to raise awareness and mobilize society about conscious consumption. The questionnaire is designed for use in studies with companies in Brazil.

The instrument was divided into two parts. The first concerned information about the respondents, such as their major, time of study, age, personal income, occupation and main form of transportation. 
The second was related to their conduct in everyday life in relation to economic, environmental and social issues and had 13 items (questions) (see Table 1). The students were asked to choose between four different options (always, frequently, rare or never). This set of items assessed the criteria of validity and reliability of the study, which was measured by the scale, based on the theoretical and practical framework of experts in the field. The questions were designed based on the constructs studied on sustainability, consisting of a code, question description, four options (always, often, rarely and never) and the initial level of difficulty of the question. That is, if more students responded to a particular issue as "always", it may be considered easier to practice and harder when fewer students responded "always". The items were validated by experts from the field of sustainability and after completion of a pre-test with 26 students in the undergraduate course in production engineering.

Table 1. Survey items, rated on a response scale of "always", "frequently", "rare" or "never".

\begin{tabular}{cl}
\hline Item & Description \\
\hline 1 & I turn off the water while washing the dishes \\
2 & I make food donations to charity organizations \\
3 & I buy products made in my region \\
4 & When I have to travel short distances, I walk \\
5 & I buy products from manufacturers that do not harm the environment \\
6 & I use the back of used sheets of paper \\
7 & I recycle garbage \\
8 & I pay more for a product that has less environmental impact \\
9 & I turn off the water while brushing my teeth \\
10 & I turn out the light when I leave a room that is no longer being used \\
11 & I turn off electronic equipment when it is not being used \\
12 & I participate in associations or social organizations in my community \\
13 & I perform volunteer work \\
\hline
\end{tabular}

The survey was conducted at a large Brazilian institute of higher education in Santa Catarina state in southern Brazil. It serves over 30,000 students with a staff of more than 1800 professors (64\% of whom have master's or PhD degrees). The sampling was based on a stratification of students of administration, law, production engineering, biology and logistics (the majors with the highest number of students), totaling 492 respondents. It is important to note that the fields of study do not have mandatory classes about sustainability, only optional ones. In the school of production engineering, students have classes focused on environmental and economic management, but not specifically on social issues. But sustainability has been discussed regularly at events, seminars and even in social projects conducted by the university.

The questionnaire was constructed in order to identify the behavior of the respondents in relation to the triple bottom line of sustainability-social, environmental and economic dimensions (Table 2) — and was carried out for each triple bottom line. Additionally, the questionnaire provides information about the respondent profile such as forms of travel, major, time of study, gender, age, family income, occupation and means of transport.

Table 2. Triple bottom line in the organizational context of sustainability.

\begin{tabular}{ccc}
\hline $\begin{array}{c}\text { Environmental } \\
\text { Dimension }\end{array}$ & Economic Dimension & Social Dimension \\
\hline $\begin{array}{c}\text { Protecting and conserving the } \\
\text { environment, care for renewable } \\
\text { resources, waste management and } \\
\text { management of risks and impacts. }\end{array}$ & $\begin{array}{c}\text { Economic results, shareholder } \\
\text { rights, competitiveness and } \\
\text { relationships between } \\
\text { customers and suppliers. }\end{array}$ & $\begin{array}{c}\text { Labor and human rights, } \\
\text { community involvement, } \\
\text { transparency and } \\
\text { ethical behavior. }\end{array}$ \\
$\begin{array}{c}\text { Respecting natural limitations, } \\
\text { rationalizing non-renewable resources, } \\
\text { optimizing the use of resources and } \\
\text { maintaining biodiversity. }\end{array}$ & $\begin{array}{c}\text { Economic development, food } \\
\text { safety, continuous } \\
\text { modernization and maximizing } \\
\text { the use of resources. }\end{array}$ & $\begin{array}{c}\text { Social inclusion, health and } \\
\text { safety, political aspects, } \\
\text { cultural aspects and } \\
\text { quality of life. }\end{array}$ \\
\hline
\end{tabular}




\section{Results and Discussion}

With the items and respondents in the same unit of measurement, it was possible to analyze their different behavior, as well as placing it on a scale.

\subsection{Descriptive Analysis—Respondents' Information}

The instrument was divided into two parts. The first part concerned the respondent information. We identified that $48.1 \%$ of respondents were male and $51.9 \%$ female. On the issue of occupation, we identified that $85.5 \%$ both study and work and $15.5 \%$ only study. Regarding their age, it was found that $56.5 \%$ are between 18 and 22 years old, $23.5 \%$ between 23 and 27 years old and the rest between 28 and 52 years old. The second part of the questionnaire sought to identify the behavior of respondents in relation to sustainable economic, environmental and social issues in their daily habits and was carried out using IRT, which is described below.

\subsection{Validation of the Construct}

The statistical test assumes as a null hypothesis that there is no difference in the information between the models. That is, to assume two dimensions does not add significant information to the model in comparison to the model with one dimension; and the alternative hypothesis assumes that there is a significant gain from the information. As can be seen in Table 3, the difference between model 1 and model 2 is statistically significant for $\alpha=0.05$, accepting the alternative hypothesis that the model that assumes two dimensions has more information than the model with one dimension. This can also be displayed in the criteria information Akaike Information Criterion (AIC) and the Bayesian Schwarz Criterion (BIC), from which it can be seen that that there are positive differences between model 1 and model 2, and between model 2 and model 3. However, in this case, it can be seen from AIC and in the AIC with a correction for finite sample sizes (AICc) that there is a positive difference between models 2 and 3, which does not occur in BIC. Since the analysis has a relatively small sample compared with the number of estimated parameters, it is suggested to use the AICc as the information criterion, since it has greater statistical strength in this case. Therefore, it is noted that when comparing the four-dimensional model with that of two dimensions, the model of three dimensions appears to be more informative than the one of four (negative AICc difference).

Table 3. Comparison of models of one, two, three and four dimensions.

\begin{tabular}{ccccccc}
\hline \multirow{2}{*}{ Models } & \multicolumn{3}{c}{ Difference Chi-Squared } & \multirow{2}{*}{ AIC } & AICc & BIC \\
\cline { 2 - 5 } & $\chi^{2}$ & $\begin{array}{c}\text { Degrees of } \\
\text { Liberty }\end{array}$ & $\boldsymbol{p}$-Value & & & \\
\hline Model 1 $\times$ Model 2 & 326.56 & 32 & $<0.01$ & 262.56 & 194.86 & 128.21 \\
Model 2 $\times$ Model 3 & 147.11 & 31 & $<0.01$ & 85.11 & 7.62 & -45.04 \\
Model 3 $\times$ Model 4 & 86.10 & 30 & $<0.01$ & 26.10 & -97.99 & -99.86 \\
\hline
\end{tabular}

Note: AIC, Akaike Information Criterion; AICc, AIC with a correction for finite sample sizes; BIC, Bayesian Schwarz Criterion.

Thus, we used the three-factor structure to evaluate the factor loads of each item. The first five eigenvalues were 3.33, 2.02, 1.23, 0.95 and 0.94 , respectively. The ratio between the first and the second eigenvalue is 1.65 , well below the minimum ratio of 3-to-1 for one-dimensionality to disappear. A statistical analysis of variance (ANOVA) was performed, confirming the existence of three dimensions, and presenting the factorial structure of the 13 items in the three dimensions, as shown in Table 4. 
Table 4. Factorial loads of the 13 items, in oblimin rotation.

\begin{tabular}{|c|c|c|c|c|}
\hline Item & Description & $\begin{array}{c}\text { Factor } 1 \\
\text { (Environmental) }\end{array}$ & $\begin{array}{l}\text { Factor } 2 \\
\text { (Social) }\end{array}$ & $\begin{array}{c}\text { Factor } 3 \\
\text { (Economic) }\end{array}$ \\
\hline 1 & I turn off the water while washing dishes & 0.614 & & \\
\hline 2 & I make food donations to charity organizations & & 0.487 & \\
\hline 3 & I buy products made in my region & & & -0.302 \\
\hline 4 & When I have to travel short distances, I walk & 0.440 & & \\
\hline 5 & $\begin{array}{l}\text { I buy products from manufacturers that do not harm the } \\
\text { environment }\end{array}$ & & & -0.613 \\
\hline 6 & I use the back of used sheets of paper & 0.400 & & \\
\hline 7 & I recycle garbage & & & -0.415 \\
\hline 8 & $\begin{array}{l}\text { I pay more for a product that has less environmental } \\
\text { impact }\end{array}$ & & & -0.749 \\
\hline 9 & I turn off the water while brushing my teeth & 0.791 & & \\
\hline 10 & $\begin{array}{l}\text { I turn out the light when I leave a room that is no longer } \\
\text { being used }\end{array}$ & 0.597 & & \\
\hline 11 & I turn off electronic equipment when it is not being used & 0.460 & & \\
\hline 12 & $\begin{array}{l}\text { I participate in associations or social organizations in my } \\
\text { community }\end{array}$ & & 0.874 & \\
\hline 13 & I perform volunteer work & & 0.802 & \\
\hline
\end{tabular}

The factorial structure presented in Table 4 was obtained with oblique oblimin rotation, and allows verifying the correlation between the factors, as can be seen in Table 5. Moreover, it can be observed that Factor 2 (social) obtained the highest scores, in particular for items 12 and 13, which indicates greater participation in voluntary and social activities. This result raises an issue highlighted by the human resources area of many companies, namely participation in volunteer activities. Müller [48] draws attention to the growth and visibility that social projects are acquiring in business, suggesting an indication that this was the strategy of choice for a significant proportion of businesses for dealing with difficulties and contradictions arising from the process of organizational legitimation, considering that companies are social and political actors in contemporary society [48].

Table 5. Correlation matrix between the three factors with oblimin rotation.

\begin{tabular}{lccc}
\hline & Factor 1 & Factor 2 & Factor 3 \\
\hline Factor 1 & 1.000 & 0.043 & -0.337 \\
Factor 2 & 0.043 & 1.000 & -0.328 \\
Factor 3 & -0.337 & -0.328 & 1.000 \\
\hline
\end{tabular}

Meanwhile, Table 3 highlights that Factor 1 (environmental) also needs to be evaluated and even introduced in courses at educational institutions, as described by Laessoe and Mochizuki who affirm that schools need to offer ways to address political, social and ethical implications of climate change [19]. These authors maintain that it is a difficult but important task for education to promote proactive responses to climate change.

Meanwhile, the environmental issues [1,4,6,9-11] had better average participation. Questions related to the use of water, energy and automobiles seem to have a greater awareness among students. This aspect is particularly conducive to the discussion in view of the fact that the environmental performance of a company is associated with the quality of its human resources. Likewise, the encouragement of behavior and awareness focused on environmental issues should be the first step in the integration of human resources and environmental management of a company [48].

Table 5 indicates that the correlation between the variables is low, theoretically allowing the bi-factorial structure. The interpretation of the factors shows that Factor 1 groups items related to questions associated with natural resources, Factor 2 groups items associated with social concern and Factor 3 to financial issues. This structure corroborates the results of Dao et al. [1],which define three dimensions related to sustainable performance: (1) environmental performance-planet; 
(2) economic performance-profitability; and (3) social performance- - people. The value of Cronbach's alpha found for the group of 13 items was 0.701, which makes the group acceptable [1].

Based on these dimensions, Benedetti et al. [43], Dale and Newman [46] and Baumgartner and Korhonen [47] affirm that for sustainable actions to become effective in the organizational environment, it is necessary to understand and identify needs with a focus on balancing the social, environmental and economic conditions, that is, the concept of sustainability has come to focus on development, not only on growth. This involves seeking economic growth that is allied to society's needs, while preserving the environment $[46,47]$.

\subsection{Discussion}

Based on the results of the exploratory factorial analysis presented above, we assumed that the most appropriate model for data processing and creation of a scale using IRT is multidimensional. Since the correlations between the three dimensions were low, as can be seen in Table 5, the bi-factorial model can be adjusted. In this manner, the non-hierarchical models were estimated - the compensatory model of two parameters for ordinal data and the bi-factorial hierarchical model also for ordinal data [21,49]. The first assumes that the three dimensions are correlated and compensatory, but the second assumes that there is a general dimension that is correlated with all three dimensions, yet these three dimensions are orthogonal between themselves.

This step was estimated with the aid of the MIRT package of the statistical computing programming language and environment $R$, with the mirt command and bfactor [50,51]. The two models were compared using ANOVA and the information criteria AIC, AICc and BIC. The results can be seen in Table 6.

Table 6. Result of the comparison test of the two-factor and compensation models.

\begin{tabular}{ccccccc}
\hline Model & AIC & AICc & BIC & $\chi^{2}$ & df & $p$-Value \\
\hline Hierarchical-bi-factorial & $13,128.52$ & $13,148.67$ & $13,401.43$ & & & \\
Non-hierarchical-compensatory & $13,140.13$ & $13,167.53$ & $13,455.01$ & 8399 & 10 & 0.590 \\
\hline
\end{tabular}

Table 6 indicates that the two-factor hierarchical model is better suited to the data than the non-hierarchical compensatory model, because the hypothesis test shows that there is significant difference between the models $(p>0.05)$ and all the criteria information indicate the superiority of the two-factorial hierarchical model. Therefore, the IRT model used in this paper is the bi-factorial.

The estimated bi-factorial model converged with a total of 456 interactions, and a stopping criterion of 0.00010 . Table 7 shows the estimate of the parameters for the 13 items, assuming the confirmatory structure indicated in the factorial analysis.

Table 7 shows that the three most discriminating items in overall size were, in descending order, item 5, item 8 and item 7, which are all in the economic dimension (dimension 3). Within specific dimensions we note that dimension 2 , which represents social concern, showed the highest discrimination power, and this is an important issue for human resources in its integration with the dimension of sustainability, in view of the strategic nature of these actions. In this sense, it is observed that, with regard to volunteer actions and participation in civil society organizations, the values presented stand out. The fact that the students had been previously involved in these social projects is an important vector, since this experience has been increasingly valued by organizations when evaluating a curriculum.

This involvement of students in social projects is of particular significance when one considers Steiner and Posch's argument about the complexity of the practical understanding of the interaction between aspects that integrate the sustainability tripod. Thus, explaining to students how sustainability works is also a complex task [52]. 
Table 7. Result of the characteristic surface of the item.

\begin{tabular}{cccccccc}
\hline Item & $\mathbf{a g}$ & $\mathbf{a 1}$ & $\mathbf{a} 2$ & $\mathbf{a} 3$ & $\mathbf{b} \mathbf{1}$ & $\mathbf{b} 2$ & $\mathbf{b 3}$ \\
\hline 1 & 0.808 & 1.285 & & & -0.054 & 1.050 & 2.317 \\
2 & 0.852 & & 1.071 & & -2.022 & -0.891 & 1.231 \\
3 & 0.679 & & & 0.392 & -2.263 & 0.346 & 3.569 \\
4 & 0.339 & 0.696 & & & -0.520 & 0.877 & 2.891 \\
5 & 1.962 & & & 1.268 & -1.849 & 0.164 & 2.459 \\
6 & 0.757 & 0.569 & & & -0.463 & 0.818 & 2.726 \\
7 & 1.261 & & & 0.641 & -0.855 & 0.240 & 1.796 \\
8 & 1.488 & & & 0.049 & -2.335 & -0.812 & 1.370 \\
9 & 0.639 & 1.954 & & & 0.416 & 1.161 & 2.180 \\
10 & 0.705 & 1.124 & & & 0.609 & 2.163 & 3.816 \\
11 & 0.486 & 0.797 & & & -0.235 & 1.142 & 3.016 \\
12 & 0.729 & & 2.844 & & -1.663 & 0.970 & 0.164 \\
13 & 0.711 & & 2.132 & & -1.676 & -0.787 & 0.520 \\
\hline
\end{tabular}

Note: ag, coefficient of general discrimination; a1, coefficient of environmental discrimination; a2, coefficient of social discrimination; a3, coefficient of economic discrimination; b1, coefficient of environmental difficulty; b2, coefficient of social difficulty; b3 coefficient of economic difficulty.

One of the main implications is that traditional educational processes are of very limited use when considering education for sustainable development, in which learning about real cases involving interdisciplinary perspectives is required $[15,53]$. That is, in addition to the capabilities of analysis and the planning essential for resolving a problem, dealing with the complexity of sustainability requires creativity and social and communication skills specific to accomplishing the change $[52,53]$.

The parameter (di) represents the difficulty a person has in reaching the point of inflection of the curve for category $\mathrm{k}$. In multidimensional models the interpretation of this non-trivial parameter can generate ambiguities [12]. However, by setting the axis of the coordinates assuming $\theta 1=0$ and $\theta 2=0$, these parameters may be used to compare the probabilities of obtaining a response in a certain category. Therefore, an increase in this parameter corresponds to a greater requirement of the individual so that a reply is given to that category. That is, an individual with an average attitude level (on the scale represented by the value 0 ) in item 3 is more likely to lower their score in this case by answering that they turn off the water when washing dishes. In response to item 4, this same individual is most likely to respond with the second category, i.e., they rarely donate food to charity organizations. Therefore, one can say that the results concerning these two items still do not indicate sustainable behaviors, indicating a need for increased attention by companies for training and awareness about these issues.

Concerning universities, Jabbour et al. presented the importance of sustainability being inserted through teaching, research and extension, as well as by the development of practical cases, while simultaneously considering the multidimensional aspects of subjects (teaching) [54]. This has profound implications for Brazilian universities, since encouragement for these practices in course syllabuses is still very low, leading to a lack of compatibility with actions at companies that are already implementing sustainability practices, such as environmental management [54].

Table 7 shows the characteristic surface of item 7 . The rotation of the figure indicates the general dimension ( $\theta 1)$, in which it is possible to identify four surfaces, which represent the probability of a response in each category. Since it is an ordinal scale, the first category is presented on the left part of the scale (the negative part). Therefore, individuals in this region of the scale have a greater probability of responding with this category. As the scale increases, it is noted that the probability of responding with this first category diminishes, consequentially increasing the probability of answering with the second category and later the third and fourth category. Since this item presented high parameters of discrimination for both the general dimension and the specific dimension, the graph (Figure 2a) is equal in the two dimensions. 


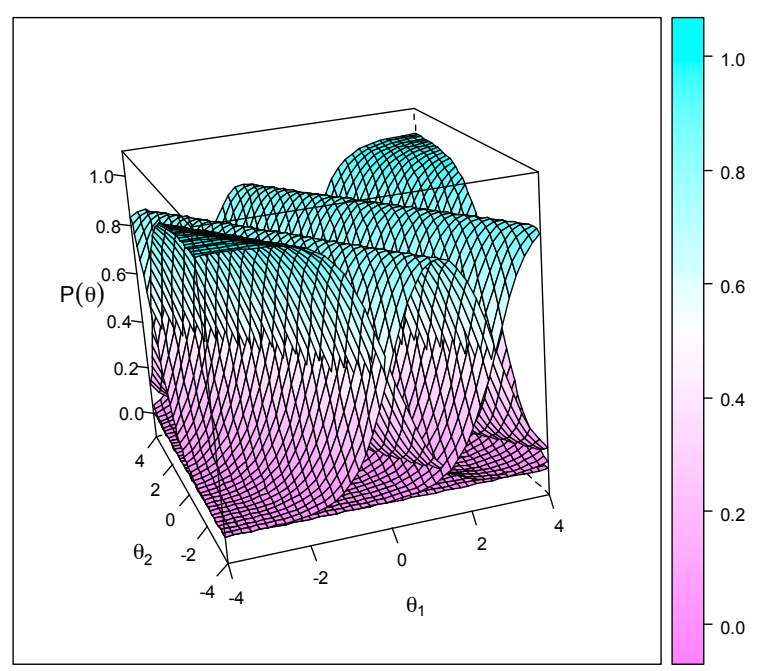

(a)

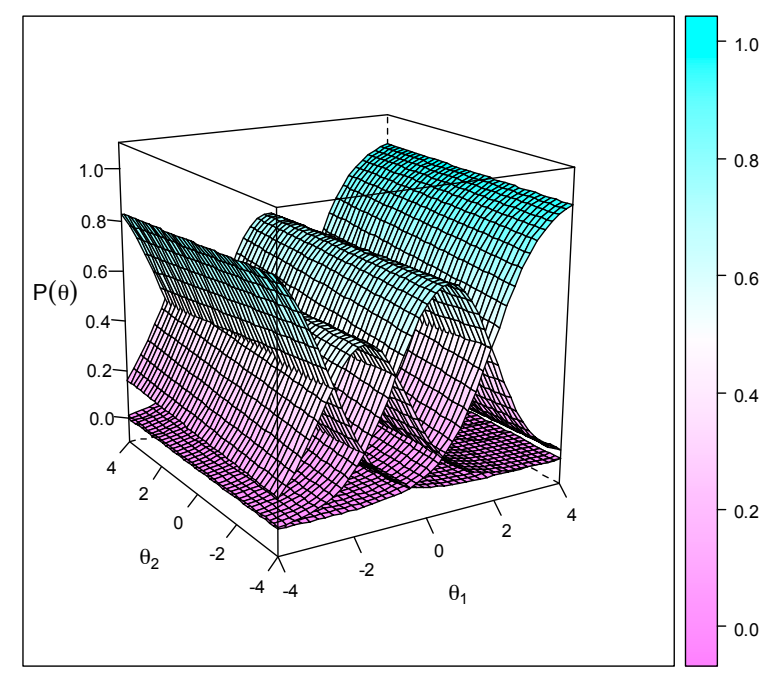

(b)

Figure 2. (a) Characteristic surface of item 7; (b) characteristic surface of item 10.

Nevertheless, it is important to note in Figure 2a,b that items 7 and 10 have a smaller percentage of positive responses. That is, when we asked if "they buy products from manufacturers that do not harm the environment" and if "they pay more for products that have a lower impact on the environment," the answer is seldom or never. As a consequence, it is observed that students tend to have more basic social and environmental behaviors in their daily lives, such as volunteer work, making donations, and garbage recycling. On the other hand, when it comes to economic aspects, such as analyzing and buying based on price and local production, sustainable aspects are not considered in decision-making. In this sense, we observe the predominance of individualist thought and practice, instead of a collective approach.

This item showed high discrimination in the overall size $(\theta 1)$ and low discrimination in the specific dimension $(\theta 2)$ causing the surface to present itself more to the overall size, with little discrimination to specific dimension.

From another perspective, Brundiers et al. analyzed the literature related to sustainability in education to determine how much real-world learning opportunities can contribute to building skills that develop sustainability. The authors also describe that for academics to engage in these opportunities, universities must incorporate collaborative projects in their courses, integrating all academic stakeholders in sustainability activities beginning with introductory courses [55]. In other words, from the freshmen year until graduate school, students should take courses that present sustainability practices and experiences.

In this context, an understanding of approaches has been discussed in relation to the analysis of the participation of companies and their practices for sustainable development, but little has been practiced at universities. The theory affirms that sustainable practices must be part of the business strategy of companies, such as best business practices to meet and balance the stakeholders. Furthermore, the theory recognizes that each company is unique, and that its choice of approaches and practices should be based on its particular business and needs, and on an understanding of the needs of the community or citizens who are direct beneficiaries of projects and actions, but these theories have not found resonance in educational institutions.

However, numerous researchers [53-56] have affirmed that for organizations to respond fully to the environmental, social and economic challenges of today, they will have to undergo significant and transformative changes. Accordingly, university students could represent part of this cultural change if they participate in environmental projects in their classes. Universities can provide important support and encourage initiatives of sustainable practices and the establishment of new standards, 
and therefore contribute more effectively to sustainable development. Sustainable behavior must be cultivated through learning and reflection, which are consequently translated into action, which can be reinforced by teaching, research and extension.

In this paper, IRT was used to represent the probability that a respondent (the subjects studied) would give a certain response to an item as a function of the parameters of the item and the skill of the respondent, noting that the greater the ability of the respondent, the greater the possibility to reach the correct answer. In this context, the study of the students showed a high level of participation in social practices, average involvement in environmental practices and low results in relation to economic issues. It also showed that the skills of scholars in the environmental and the economic factors need to be reinforced by the universities and, consequently, by the companies in training actions.

\section{Conclusions}

This article presented a study that allows analyzing sustainable behavior of potential professionals, using the multidimensional approach of IRT. The results of this study show that the social dimension, indicated in the issues "I participate in social organizations in my community" and "I do volunteer work", followed by the issue "I turn off the water while I brush my teeth" in the environmental dimension, were the questions with the highest results among the students participating in the study. Meanwhile, the questions with lower results were those in the economic dimension, with questions such as "I pay more for products that have lower environmental impact", "buy products that do not harm the environment" and "buy products developed in the region". This result is in keeping with that found by authors cited in this article, who describe the growth and visibility that many companies are giving to insertion in social projects and volunteer work in their sustainability practices. Questions related to water, energy and use of a car appear to present greater awareness among the students. That is, although the social dimension was higher, when the factorial structure was analyzed, questions related to the environment (use of water, energy and a car), had good averages. In addition, it is important to highlight that these results can also be related to the fact that the students were in courses that do not have required classes about sustainability, as described in the methodology, except for the course in production engineering, which has classes in the environment in the context of a company.

In relation to the comparison of results with the use of IRT, the strength of the relationship between the responses and the corresponding latent trait can be observed, as well as the steering of actions that should be conducted for one or more items to be met in relation to the latent trait. The results also show that with the increased discrimination of an item there was an increase in the capacity to differentiate individuals with different levels of sustainable attitudes. This constitutes an important question in the field of human resources, particularly in relation to the awareness and training of professionals, not only at the company, but also in social activities, considering culture, principles and beliefs.

MIRT is designed to be a tool capable of describing the generally non-trivial apparatus of abilities or another latent characteristic, such as the sustainable behavior of a person, thus generating a diagnostic tool of various aspects of the phenomenon and is capable of modeling the interaction between the people examined and the items. This approach has been gaining space in the literature as an alternative to traditional techniques of multidimensional approaches to latent traits [52].

For future studies, there is a clear need for new research involving a higher number of students and from courses in different educational fields, as well as at different universities, to determine if there is a differentiation or not among future professionals. To do so, studies using the same line of questions are suggested with larger samples and even applied in different countries, to evaluate the social-cultural issues as factors that influence the results.

Author Contributions: Vanderléia M. Lohn structured the paper, contributed to the definition of the theoretical basis, developed and applied the research instrument and analyzed the results. Rafael Tezza was responsible for entering the research data into the IRT software and describing the results, he also contributed to the analysis of the results. Graziela D. Alperstedt contributed to the analysis of the results, especially in the areas of strategies, human resources and sustainability. Lucila M. S. Campos structured the paper and also contributed to the definition of 
the theoretical basis, analysis and discussion of the results, especially in the area of sustainability. All authors wrote and revised the article. All authors have read and approved the final manuscript.

Conflicts of Interest: The authors declare no conflict of interest.

\section{References}

1. Dao, V.; Langella, I.; Carbo, J. From green to sustainability: Information technology and integrated sustainability framework. J. Strateg. Inf. Syst. 2011, 20, 63-79. [CrossRef]

2. Colbert, B.A.; Kurucz, E.C. Three conceptions of triple bottom line business sustainability and the role for HRM. Hum. Resour. Plan. 2007, 30, 21-29.

3. Porter, M.; Kramer, M. Strategy and society: The link between competitive advantage and corporate social responsibility. Harv. Bus. Rev. 2006, 12, 78-92.

4. Searcy, C.; Elkhawas, D. Corporate Sustainability Ratings: An Investigation into How Corporations Use the Dow Jones Sustainability Index. J. Clean. Prod. 2011, 35, 79-92. [CrossRef]

5. Chow, W.S.; Chen, Y. Corporate Sustainable Development: Testing a New Scale Based on the Mainland Chinese Context. J. Bus. Ethics 2012, 105, 519-533. [CrossRef]

6. Gurvitsh, N.; Sidorova, I. Survey of Sustainability Reporting Integrated into Annual Reports of Estonian Companies for the years 2007-2010: Based on Companies Listed on Tallinn Stock Exchange as of October 2011. Procedia Econ. Financ. 2012, 2, 26-34. [CrossRef]

7. Glavas, K.; Kelley, K. The Effects of Perceived Corporate Social Responsibility on Employee Attitudes. Bus. Ethics Q. 2014, 24, 165-202. [CrossRef]

8. Gonzalez-Benito, J.; Gonzalez-Benito, O. Environmental proactivity and business performance: An empirical analysis. Omega Int. J. Manag. Sci. 2005, 33, 1-15. [CrossRef]

9. Darnall, N.; Jolley, G.J.; Handfield, R. Environmental management systems and green supply chain management: Complements for sustainability? Bus. Strateg. Environ. 2008, 17, 30-45. [CrossRef]

10. Aguinis, H.; Glavas, A. What we know and don't know about corporate social responsibility: A review and research agenda. J. Manag. 2012, 38, 932-968. [CrossRef]

11. Zelezny, L.C.; Schultz, P. Psychology of promoting environmentalism: Promoting environmentalism. J. Soc. 2000, 56, 365-371. [CrossRef]

12. Ferdig, M.A. Sustainability leadership relational model and practices, 2009. Sustainability Leadership Institute. Available online: http://www.sustainabilityleadershipinstitute.org/downloads/SLI_model_ download.pdf (accessed on 3 October 2015).

13. Mudrack, P. Individual personality factors that affect normative beliefs about the rightness of corporate social responsibility. Bus. Soc. 2007, 46, 33-62. [CrossRef]

14. Schwartz, S.H.; Cieciuch, J.; Vecchione, M.; Davidov, E.; Fischer, R.; Beierlein, C.; Ramos, A.; Verkasalo, M.; Lönnqvist, J.E.; Demirutku, K.; et al. Refining Basic Values Theory. J. Personal. Soc. Psychol. 2012, 103, 663-688. [CrossRef] [PubMed]

15. Bansal, P. From issues to actions: The importance of individual concerns and organizational values in responding to natural environmental issues. Organ. Sci. 2003, 14, 510-527. [CrossRef]

16. Hay, R.; Gray, E. Social responsibilities of business managers. Acad. Manag. J. 1974, 17, 135-143. [CrossRef]

17. Swanson, D.L. Toward an integrative theory of business and society: A research strategy for corporate social performance. Acad. Manag. Rev. 1999, 24, 506-521.

18. Stevens, J.M.; Steensma, H.K.; Harrison, D.A.; Cochran, P.L. Symbolic or substantive document? The influence of ethics codes on financial executives' decisions. Strateg. Manag. J. 2005, 26, 181-195. [CrossRef]

19. Laessoe, J.; Mochizuki, Y. Recent Trends in National Policy on Education for Sustainable Development and Climate Change Education. J. Educ. Sustain. Dev. 2015, 9, 27-43. [CrossRef]

20. Elkington, J. Canibais com Garfo e Faca; M.Books do Brasil Editora: São Paulo, Brazil, 2012.

21. Andrade, D.F.; Tavares, H.R.; Valle, R.C. Item Response Theory: Concepts and Applications; Associaçao Brasileira de Estatística: São Paulo, Brazil, 2000. (In Portuguese)

22. Jorge, M.L.; Martinez, D.M.; Reyes, M.J. Que habría de incluir una memoria completa de sostenibilidad? Univ. Bus. Rev. 2013, 39, 1698-5117.

23. Jabbour, C.J.C.; Santos, F.C.A. The central role of human resource management in the search for sustainable organizations. Int. J. Hum. Resour. Manag. 2008, 19, 2133-2154. [CrossRef] 
24. Eisenstat, R. What Corporate Human Resources Brings to the Picnic: Four Models for Functional Management. Organ. Dyn. 1996, 25, 7-22. [CrossRef]

25. Wright, C.; Nyberg, D.; Grant, D. Hippies on the third floor: Climate Change, Narrative Identity and the Micro-Politics of Corporate Environmentalism. Organ. Stud. 2012, 33, 1451-1475. [CrossRef]

26. Marcus, A.A.; Fremeth, A.R. Green Management Matters Regardless. Acad. Manag. Perspect. 2009, 23, 17-26.

27. Wright, P.M.; Boswell, W. Desegregating HRM: A Review and Synthesis of Micro and Macro Human Resource Management Research. J. Manag. 2002, 28, 247-276. [CrossRef]

28. Wirtenberg, J.; Harman, J.; Russell, W.; Fairfield, K. HR's role in building a sustainable enterprise: Insights from some of the world's best companies. Hum. Resour. Plan. 2007, 30, 10-20.

29. Fenwick, T.; Bierma, L. Corporate social responsibility: Issues for human resource development professionals. Int. J. Train. Dev. 2008, 12, 24-35. [CrossRef]

30. Singh, J. Tackling measurement problems with Item Response Theory: Principles, characteristics, and assessment, with an illustrative example. J. Bus. Res. 2004, 57, 184-208. [CrossRef]

31. Wang, M.; Russell, S.S. Measurement equivalence of the Job Descriptive Index across Chinese and American workers: Results from confirmatory factor analysis and item response theory. Educ. Psychol. Meas. 2005, 65, 709-732. [CrossRef]

32. Zickar, M.J. Conquering the next frontier: Modeling personality data with item response theory. In Applied Personality Psychology: The Intersection of Personality and I/O Psychology; Roberts, B., Hogan, R., Eds.; American Psychological Association: Washington, DC, USA, 2001; pp. 141-158.

33. Zickar, M.J.; Robie, C. Modeling faking good on personality items: An item-level analysis. J. Appl. Psychol. 1999, 84, 551-563. [CrossRef]

34. Maurer, T.J.; Raju, N.S.; Collins, W.C. Peer and subordinate performance appraisal measurement equivalence. J. Appl. Psychol. 1998, 83, 693-702. [CrossRef]

35. Tay, L.; Drasgow, F.; Rounds, J.; Williams, B. Fitting measurement models to vocational interest data: Are dominance models ideal? J. Appl. Psychol. 2009, 94, 1287-1304. [CrossRef] [PubMed]

36. Ryan, A.M.; Horvath, M.; Ployhart, R.E.; Schmitt, N.; Slade, L.A. Hypothesizing differential item functioning in global employee opinion surveys. Pers. Psychol. 2000, 53, 531-562. [CrossRef]

37. Allen, D.D.; Wilson, M. Introducing multidimensional item response modeling in health behavior and health education research. Health Educ. Res. 2006, 21, i73-i84. [CrossRef] [PubMed]

38. Holzinger, K.J.; Swineford, F. The bi-factor method. Psychometrika 1937, 2, 41-54. [CrossRef]

39. Li, Y.; Rupp, A.A. Performance of the $S-\chi^{2}$ statistic for full-information bifactor models. Educ. Psychol. Meas. 2011, 71, 986-1005. [CrossRef]

40. Gibbons, R.D.; Bock, R.D.; Hedeker, D.; Weiss, D.J.; Segawa, E.; Bhaumik, D.K.; Stover, A. Full-information item bifactor analysis of graded response data. Appl. Psychol. Meas. 2007, 31, 4-19. [CrossRef]

41. Reise, S.P.; Morizot, J.; Hays, R.D. The role of the bifactor model in resolving dimensionality issues in health outcomes measures. Qual. Life Res. 2007, 16, 19-31. [CrossRef] [PubMed]

42. Bortolotti, S.L.V. Resistência à Mudança Organizacional: Medida de Avaliação por meio da Teoria da Resposta ao Item. Ph.D. Dissertation, Universidade Federal de Santa Catarina, Centro Tecnológico, Programa de Pós-Graduação em Engenharia de Produção, Florianópolis, Brazil, 2010. (In Portuguese)

43. Benedetti, M.H.; Lima, P.; Melatto, L.; Silva, M. Possíveis interações entre o desenvolvimento sustentável e a logística de combustíveis. Rev. Prod. 2009, 19, 129-142. [CrossRef]

44. Donaire, D. Gestão Ambiental na Empresa; Atlas: São Paulo, Brazil, 1999.

45. Akatu. Consumo Consciente para um Futuro Sustentável. Available online: http://www.akatu.org.br/ (accessed on 10 January 2015).

46. Dale, A.; Newman, L. Social capital: A necessary and sufficient condition for sustainable community development? Community Dev. J. 2010, 45, 5-21. [CrossRef]

47. Baumgartner, R.J.; Korhonen, J. Strategic thinking for sustainable development. Sustain. Dev. 2011, 18, 71-75. [CrossRef]

48. Müller, L.H.A. A Construção do Social a Partir da Ótica Empresarial. V Workshop Empresa, Empresários e Sociedade: O Mundo Empresarial e a Questão Social; Anais: Porto Alegre, Brazil, 2006.

49. Muraki, E.; Carlson, J.E. Full-information factor analysis for polytomous item responses. Appl. Psychol. Meas. 1993, 19, 73-90. [CrossRef] 
50. Chalmers, R.P. Mirt: A multidimensional item response theory package for the R environment. J. Stat. Softw. 2012, 48, 1-29. [CrossRef]

51. R Core Team. R: A Language and Environment for Statistical Computing; R Foundation for Statistical Computing: Vienna, Austria, 2013; Available online: http:/ / www.R-project.org/ (accessed on 7 January 2015).

52. Steiner, G.; Posch, A. Higher education for sustainability by means of transdisciplinar case studies: An innovative approach for solving complex, real-world problems. J. Clean. Prod. 2006, 14, 877-890. [CrossRef]

53. Castro, R.; Jabbour, C.J.C. Evaluating sustainability of an Indian university. J. Clean. Prod. 2013, 61, 54-58. [CrossRef]

54. Jabbour, C.J.C.; Sarkis, J.; Jabbour, A.B.L.; Govindan, K. Understanding the process of greening of Brazilian business schools. J. Clean. Prod. 2013, 61, 25-35. [CrossRef]

55. Brundiers, K.; Wiek, A.; Redman, C.L. Emerald Article: Real-world learning opportunities in sustainability: From classroom into the real world. Int. J. Sustain. High. Educ. 2010, 11, 308-324. [CrossRef]

56. Scott, L.C.; Tinnemore, R. Is community-based sustainability education sustainable? A general overview of organizational sustainability in outreach education. J. Clean. Prod. 2009, 17, 1132-1137. [CrossRef]

(C) 2017 by the authors. Licensee MDPI, Basel, Switzerland. This article is an open access article distributed under the terms and conditions of the Creative Commons Attribution (CC BY) license (http:/ / creativecommons.org/licenses/by/4.0/). 